Research Article

\title{
Mapping of DFNB3/MYO15A in Punjabi families with non-syndromic congenital deafness.
}

\section{Nazir Ahmad ${ }^{1,2 *}$, Muhammad Qasim $^{3}$, Zubair M. Ahmed ${ }^{1,4}$ and Sheikh Riazuddin ${ }^{1}$}

1- National Centre of Excellence in Molecular Biology, University of the Punjab Lahore Pakistan

2- Department of Biology, Government Post Graduate College Civil Lines Multan Pakistan

3- Department of Bioinformatics and Biotechnology, Government College University Faisalabad Pakistan.

4- Department of Otorhinolaryngology Head \& Neck Surgery School of Medicine University of Maryland, USA

Corresponding Author: nazirahmad1976@yahoo.com

Citation

Nazir Ahmad, Muhammad Qasim, Zubair M. Ahmed and Sheikh Riazuddin. Mapping of DFNB3/MYO15A in families with non-syndromic congenital deafness. Pure and Applied Biology Vol. 4, Issue 2, 2015, pp 154-157.

Received: $12 / 04 / 2015$

Revised: 10/05/2015

Accepted: 27/05/2015

\section{Abstract}

Deafness is inherited most commonly following autosomal recessive mode of inheritance as isolated clinical finding Genetic and clinical heterogeneity of disorder prevent pooling of affected families and is a big barrier in gene mapping by conventional techniques. However, because of consanguinity, linkage analysis can be used to find disease causing loci /genes in small nuclear families. This study demonstrates the power of this technique by identifying two families segregating their disease phenotype with DFNB3/MYO15A.

\section{Introduction.}

Deafness is partial or total failure to hear or distinguish sounds and also distressed potential of speech in affected individuals. It is the most-wide spread neuro-sensory trouble in humans which affects $0.1 \%$ of the population worldwide and most of which are genetically inheritable [1]. Frequent consanguineous marriages in Pakistani population favors genetic characterization of hereditary disorders like deafness [2]. Identification of molecular components of genes by forward genetics is hard due to tremendous genetic as well as clinical heterogeneity. In this scenario, linkage analysis is a valuable technique not only for mapping new regions, but also to refine the boundaries of already identified loci [3, 4]. Exclusion analysis for known loci is helpful in refining the reported regions or detecting the variant alleles in families linked to the loci with already known gene. This study will help to offer genetic counseling to the families and to reduce the incidence of hereditary deafness in Pakistani population thereby decreasing socio-economic burden.

\section{Materials and Methods}

Families segregating non-syndromic sensorineural hearing loss were identified by an extensive search from the schools and centers for special education located in different districts of Punjab province.

A total of 10 families with three or more deafness affected individuals and segregating autosomal recessive deafness were enrolled in the study and blood samples were collected from each affected individual, normal siblings, parents and grandparents, depending upon their availability and consent. DNA was extracted from the blood samples and used in the linkage analyses by genotyping three fully informative fluorescently labeled primers (D17S2207, D17S2206 and D17S2196) used for screening of $M Y O$ 15A.Haplotypes were constructed to find the pattern of inheritance among the affected and normal individuals of each family under study. If the deafness phenotype in a family showed potential linkage to DFNB3 locus (MYO15A), more closely spaced STR markers were genotyped. Two-point LOD scores (Zmax) were calculated for each family using MLINK software.

\section{Results}

PKDF482

This family was enrolled from "Gujrat" and belongs to caste "Arian". It has four affected individuals in two sib ships (Fig.1). Hearing loss in this family was also non-syndromic as there was no history other obvious clinical abnormality. 


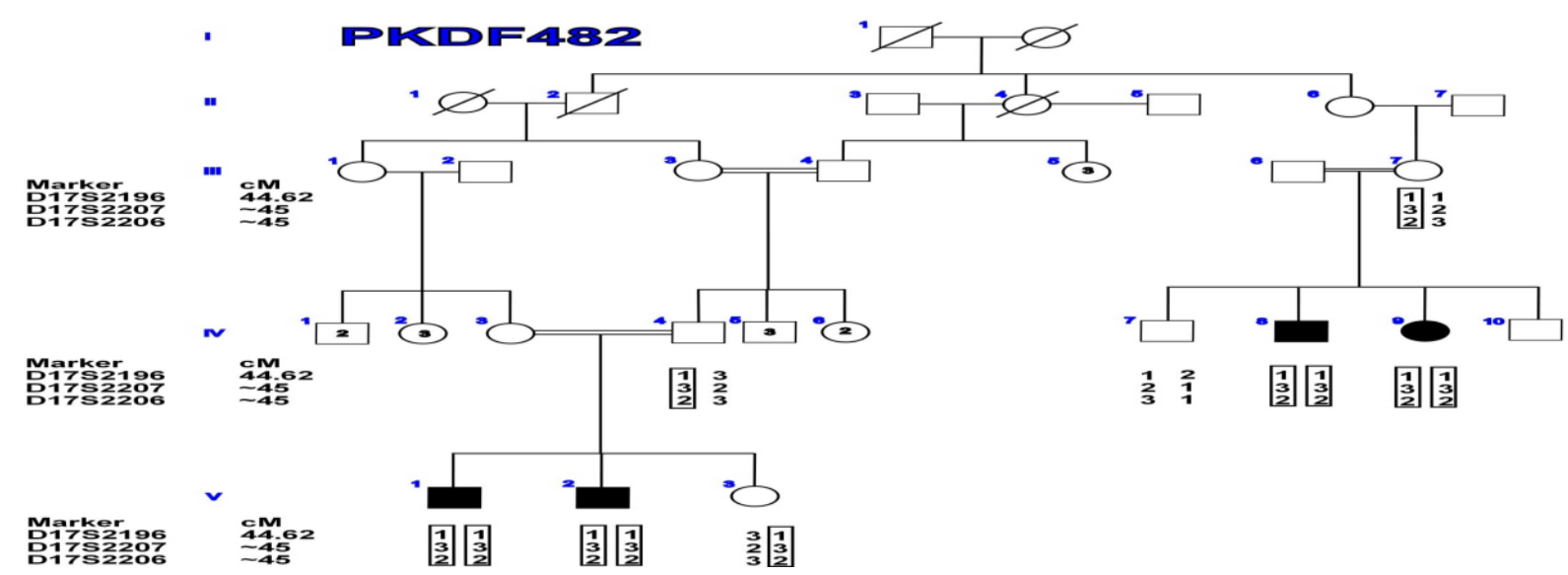

Fig. 1. DFNB3 linked haplotype in family PKDF482at chromosome 17. Black symbols represent individuals who are deaf. The 'at risk' haplotypes are boxed in all generations. The genetic linkage markers and their relative positions in centimorgans (cM) according to the Marshfield maps are shown on the left side of the pedigree.

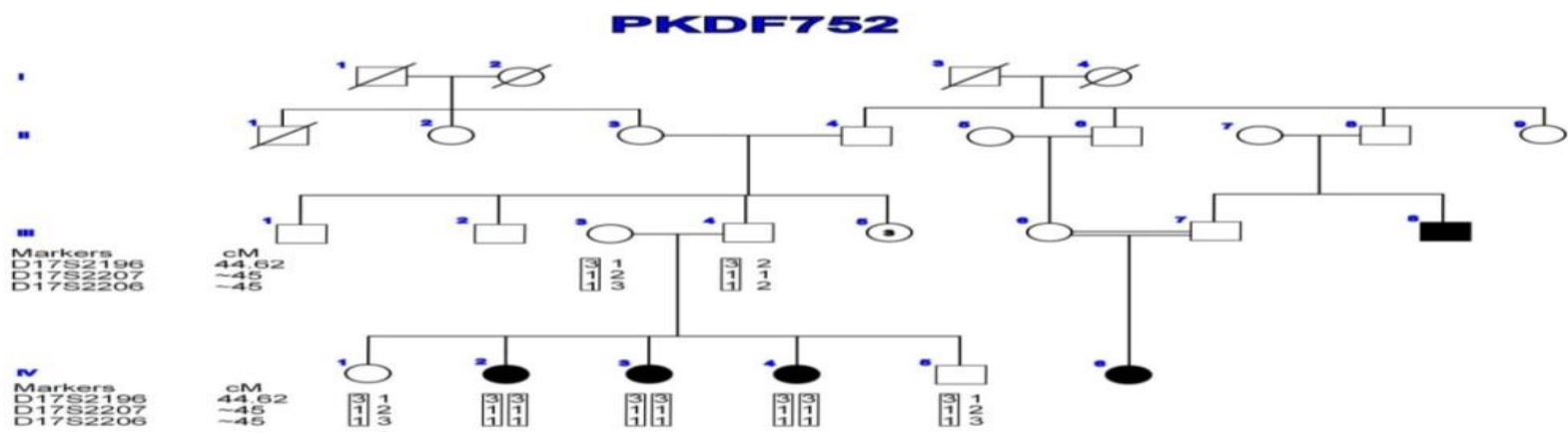

Fig. 2. DFNB3 linked haplotype in family PKDF752 at chromosome 17. Black symbols represent individuals who are deaf. The 'at risk' haplotypes are boxed in all generations. The genetic linkage markers and their relative positions in centimorgans (cM) according to the Marshfield maps are shown on the left side of the pedigree.

Haplotype construction established the linkage to DFNB3 locus with the markers D17S2207, D17S2206 and D17S2196. Zmax of 3.2 was observed for the markers D17S2207 and D17S2206 and 2.70 for the marker D17S2196.

\section{PKDF752}

PKDF752 belonging to "Arian" caste was ascertained from Faisalabad (Punjab) and contains five affected members in three sib ships but only three of them, belonging to one loop could be included in this study. Physical evaluation of affected individuals revealed the absence of any other abnormality associated with hearing loss. During linkage analysis, this family was mapped to the DFNB3 interval on chromosome 17 (Fig.2). Maximum two point LOD score of 1.5 was obtained from the markers D17S2196, D17S2206 and D17S2207 at recombination fraction $\theta=0$.

Discussion.
The linkage studies of hereditary hearing loss offer a unique canvas to draw two types of illustrations all together-First, identification of the causative genes and the underlying pathogenic process in each form of deafness and-Second, elucidation of the molecular and cellular mechanisms of hearing.

The present study was aimed at to identify families that are linked with DFNB3/Myo15A. To achieve this objective, 10 consanguineous families, segregating deafness trait were ascertained from different areas of Gujrat and Faisalabad. These families were subjected to linkage analysis by using highly polymorphic microsatellite markers for $D F N B 3$.Deafness phenotypes in two of these families were linked to the reported locus DFNB3.

The deafness phenotype segregating in two pedigrees PKDF482 and PKDF752 were found linked to $D F N B 3$. This locus was initially mapped by 
Friedman et al., (1995) to chromosome 17 with the help of a large non-consanguineous Indonesian pedigree and, later, MYO15A was identified as the underlying causative gene $[5,6]$. This gene consists of 66 coding exons for MYOSIN XVA protein having 3530 amino acid residues. MYOSIN XVA is found to be concentrated within the cuticular plate and stereocilia of cochlear sensory hair cells of adult mouse and plays role in the formation and maintenance of the unique actin-rich structures of inner ear sensory hair cells [7]. Recessive mutations of $M Y O 15 A$ are associated with profound, nonsyndromic deafness DFNB3 in humans, and deafness with vestibular dysfunction in Shaker 2 mice [8]. Mutant alleles of MYO15A are responsible for 5\% recessive deafness in Pakistani population $[9,10]$.

\section{Conclusion.}

Myo15A segregates with non-syndromic hearing loss in our population and its mapping in our population verifies the significance of Pakistani population as the best genetic resource for characterization of hereditary disorders. These linked families can be subjected to mutational analysis of Myo15A to detect the underlying disease causing alleles.

\section{Acknowledgements.}

We are grateful to deaf families throughout the Punjab province of Pakistan for their cooperation in sharing family and disease history and giving voluntarily blood samples.

\section{References}

1. Morton CC, \& Nance WE (2006). Newborn Hearing Screening — A Silent Revolution. N Engl J Med 354:2151-64

2. Hussain R, \& Bittles AH (1998). The prevalence and demographic characteristics of consanguineous marriages in Pakistan. J Biosoc Sci 30:261-275.

3. Friedman TB, \& Griffith AJ (2003). Human nonsyndromic sensorineural deafness. Annu Rev Genomics Hum Genet 4:341-402.

4. Woods CG, Cox J, Springell K, Hampshire DJ, Mohamed MD, McKibbin M, Stern R, Raymond F. L, Sandford R, Sharif S, Karbani G, Ahmed M,
Bond J, Clayton D, Inglehearn CF (2006). Quantification of homozygosity in consanguineous individuals with autosomal recessive disease. Am J Hum Genet 78(5):889-96.

5. Friedman TB, Liang Y, Weber JL, Hinnant JT, Barber TD, Winata S, Arhya IN, \&Asher JH (1995). A gene for congenital, recessive deafness DFNB3 maps to the pericentromeric region of chromosome 17. Nat Genet, 9:86-91.

6. Wang A, LiangY, Fridell RA, Probst FJ, Wilcox ER, Touchman JW, Morton CC, Morell RJ, Noben-Trauth K, Camper SA, Friedman TB (1998). Association of unconventional myosin MYO15 mutations with human nonsyndromic deafness DFNB3. Sci 280:1447-1451.

7. Liang Y, Wang A, Belyantseva IA, Anderson DW, Probst FJ, Barber TD, Miller W, Touchman JW, Jin L, Sullivan SL, Sellers JR, Camper SA, Lloyd RV, Kachar B, Friedman TB, Fridell RA (1999). Characterization of the human and mouse unconventional myosin XV genes responsible for hereditary deafness DFNB3 and shaker 2 . Genomics 61:243-258.

8. Wang A, LiangY, Fridell RA, Probst FJ, Wilcox ER, Touchman JW, Morton CC, Morell RJ, Noben-Trauth K, Camper SA, Friedman TB(1998). Association of unconventional myosin MYO15 mutations with human nonsyndromic deafness DFNB3. Sci 280:1447-1451.

9. Liburd N, Ghosh M, Riazuddin S, Naz S, Khan S, AhmedZ, Riazuddin,S, Liang Y, Menon PS, SmithT, Smith AC, Chen KS, Lupski JR, Wilcox ER, Potocki L, Friedman TB (2001). Novel mutations of MYO15A associated with profound deafness in consanguineous families and moderately severe hearing loss in a patient with Smith-Magenis syndrome. Hum Genet 109:535-541.

10. Nal N, Ahmed, ZM., Erkal E, Alper, OM, Lüleci G, Dinç O, Waryah AM, Ain Q, Tasneem S, Husnain T, Chattaraj P, Riazuddin S, Boger E, Ghosh M, Kabra M, Riazuddin S, Morell RJ, Friedman TB (2007). Mutational spectrum of MYO15A: the large $\mathrm{N}$-terminal extension of MYOSIN XVA is required for hearing. Hum Mutat, 28(10):1014-1019. 